\title{
LA LLAMADA "GARANTÍA JUVENIL" (WARRANTY FOR YOUNG) EN EUROPA Y SU INSTRUMENTACIÓN EN ESPAÑa
}

The warranty for young in Europe and its implementation in Spain

\author{
Belén del Mar López InSua
}

Profesora Doctora del Departamento de Derecho del Trabajo y de la Seguridad Social. Universidad de Granada. E-mail: blinsua@ugr.es.

\section{RESUMEN}

La grave situación de crisis económica y financiera mundial ha golpeado a todos los estractos de la sociedad, siendo el colectivo de los jóvenes el más perjudicado por esta lacra. Las terribles consecuencias que ha causado este fenómeno se han visto reflejadas en un mercado de trabajo debilitado en donde ahora reinan los principios de precariedad, desprotección, desorientación y desmotivación laboral. La alarmante cifra de desempleo juvenil ha preocupado enormemente a la Unión Europea, es por ello que todos sus esfuerzos se hayan centrado en la consolidación de una Europa económicamente más fortalecida y comprometida con el futuro laboral de sus jóvenes. Tras diversas iniciativas y conatos legislativos, finalmente, se ha aprobado la "Garantía Juvenil".

Palabras Clave: Garantía Juvenil. Desempleo. Emprendimiento.

\begin{abstract}
The critical situation suffered worldwide because of the current economical and financial crisis has struck all the social layers, from which it has especially impaired the group composed by the young. This fact has prompted awful consequences in a weakened labour market, where precariousness, confusion and lack of legal protection and motivation freely rule. The high rates of youthful unemployment have strongly concerned the European Union for the last years and so, it has focused all its efforts to economically consolidate an Europe much more committed to provide a reliable labour future for its young people. After several legal trials it has finally approven the named "Garantía Juvenil" ("Warranty for young").
\end{abstract}




\section{KEYWORDS: WARRANTY FOR YOUNG. UNEMPLOYMENT. BUSINESS VENTURE.}

SumARIO: Introducción. 1. Respuestas e iniciativas comunitarias frente al desempleo juvenil: la denominada "garantía juvenil". 2. El establecimiento de un marco jurídico-político para el crecimiento del empleo juvenil en españa: la ley de emprendedores. 2.1. Plan de medidas de políticas de empleo en españa. 2.2. Las leyes de medida y apoyo al emprendimiento. Conclusiones. Bibliografía.

"El Estado democrático del trabajo se basa en la idea fundamental de que la conservación y evolución de la existencia individual, la propagación de la especie y, finalmente, la tutela de la vida, de la integridad física y de la salud, que son para los individuos las finalidades más importantes, deben también considerarse como la razón y misión primera de toda actividad del Estado"(MENGER, 2004)1.

\section{INTRODUCCIÓN}

Desde que la crisis llamó a nuestra puerta a principios del año 2008, todos hemos sido testigos de los efectos devastadores que este fenómeno económico ha originado y aún continúa causando tanto a nivel nacional, como a escala mundial. Constantemente vemos como son más y más las personas que ven extinguidos sus contratos de trabajo o, incluso, el cese de su actividad por el cierre de la empresa en la que trabajaban, y como ahora se encuentran en las largas listas del paro. Esta crispada situación se ha traducido en un crecimiento exponencial y de larga duración de los niveles de desempleo, debido todo ello a la caída de la actividad productiva.

La crisis económica ha golpeado en todas las capas de sociedad, pero sin duda, ha sido el colectivo de los jóvenes uno de los más afectados. La situación ha sido particularmente aguda en ciertas regiones y Estados miembros en donde las tasas de desempleo juvenil se han visto incrementadas significativamente ${ }^{2}$, habiéndose

${ }^{1}$ Menger, A.: El Estado democrático del trabajo, edición y estudio preliminar, "Derechos sociales y Estado democrático en Anton Menger", a cargo de J. L. Monereo Pérez, Granada, Ed. Comares, 2004, pag. 177.

${ }^{2}$ Según publica el Eurostat: en abril de 2013 la tasa de desempleo juvenil alcanzó el 23,5\% en el conjunto de los 27 Estados miembros. Más aún, entre los distintos Estados miembros e incluso entre las regiones de un mismo Estado las diferencias son significativas, así pues: mientras que en algunos Estados miembros la tasa de desempleo juvenil ronda el 50\% y supera el $70 \%$ en algunas regiones, en otras, la tasa se sitúa muy por debajo del $5 \%$. Mucho más importante aún, actualmente más de 7,5 millones de jóvenes de menos de 25 años no se 
con todo ello experimentado una lamentable pérdida de inmensos costes humanos y sociales $^{3}$. Lo cual ha supuesto una seria amenaza para la cohesión social, así como un incremento de la inestabilidad política ${ }^{4}$.

El predominio de la precariedad laboral, la desorientación, la falta de formación y la desmotivación ${ }^{5}$, son problemas que están latentes a día de hoy en el grupo de jóvenes que forma parte de la Unión Europea. De ahí que a la hora de adentrarnos en la identificación del desempleo juvenil, tengamos que hablar de dos subgrupos de jóvenes con importantes riesgos de exclusión social: de un lado, aquellos que ni estudian, ni trabajan, ni tienen, ni buscan un empleo (los "ni-ni") ${ }^{6}$; y de otro lado, los trabajadores pobres, cuyas condiciones salariales son extremadamente precarias y cuyos contratos de trabajo tienen un carácter de temporalidad limitada (MONEREO PÉREZ, 2009, p.111 y HERNÁNDEZ BERAJANO, 2013, p. 281 Y 282).

\section{RESPUESTAS E INICIATIVAS COMUNITARIAS FRENTE AL DESEMPLEO JUVENIL: LA DENO- MiNADA "GaRANTÍA JuVENIL"}

La economía comunitaria se encuentra atravesando un momento muy delicado debido al alto nivel de endeudamiento y al deterioro de sus fundamentos, lo que se refleja en una elevada tasa de desempleo. La clave para eliminar esa segmentación de los mercados laborales sólo será posible cuando Europa se haya sobrepuesto a la crisis económica. Para lo cual resultará imprescindible la puesta en marcha de cuatro elementos "claves" que frenen dicha caída, a saber: 1) mantener una estabilidad financiera; 2) construir un sistema económico más fuerte a través del saneamiento de las finanzas públicas y mejora de la competitividad; 3) reforzar la unión económica y monetaria, y en particular, la unión bancaria; y 4) luchar contra el desempleo y

encuentran desempeñando un empleo, una educación o una formación (Neither in employment, education or training -NEET-).

3 Véase las conclusiones del Consejo de Europa de 27 y 28 de junio del 2013 (EUCO 104/2/13 REV 2).

${ }^{4}$ En palabras del presidente del Concilio Europeo, Herman Van Rompuy, en la Cumbre europea de 27 y 28 de junio de 2013 (press.office@consilium.europea.eu http://www.consilium. europa.eu).

${ }^{5}$ Se observa en el mercado de trabajo una marcada polarización. Así pues, jóvenes con una escasa cualificación abandonan pronto sus estudios, mientras que otros altamente cualificados, están subempleados.

${ }^{6}$ Según la Encuesta de Población Activa (EPA) elaborada por el Instituto Nacional de Estadística a fecha de 24 de octubre de 2013, en España hay 445.700 jóvenes de entre 16 y 29 años que ni estudian, ni trabajan, ni buscan empleo (ello supone un 5,7\% de la población en esta franja de edad). Tres puntos más que la media europea, lo cual sitúa a España entre los tres países (junto con Bulgaria, Italia e Irlanda) con más desempleo juvenil. 
apoyar el crecimiento a corto plazo ${ }^{7}$.

Actualmente, la problemática del empleo juvenil constituye uno de los temas que más preocupan al colectivo comunitario (SURÁREZ CORUJO, 2014, p. 85). Es por ello que ocupe un lugar prioritario dentro del propio plan de trabajo de la Comisión Europea ${ }^{8}$, habiéndose así diseñado una serie de estrategias que buscan actuar a modo de plan de choque contra el desempleo, tratando además de favorecer la creación de empresas y la inserción de jóvenes en el mercado de trabajo (SEMPERE NAVARRO, 2013, p. 1).

Procurando hacer justicia a ese ambicioso objetivo, en 2010 se aprueba en la Unión Europea (UE) la "Europa 2020, una estrategia para un crecimiento inteligente, sostenible e integrador" (ISI) ${ }^{9}$. En este relevante documento, la Comisión propone a la UE una serie de pautas a largo plazo (a realizar durante el periodo 2014-2020) para hacer guiar los procesos y objetivos a conseguir por cada uno de los estados miembros ${ }^{10}$, entre los cuales se encuentra: el empleo, la educación y la lucha contra la pobreza ${ }^{11}$. Se trata, por tanto, de un ideal perfectamente alcanzable, pero que si bien requiere de la participación de todos los estados miembros, agentes

${ }^{7}$ Véase la Carta del Presidente Herman Van Rompuy a los miembros del Consejo Europeo sobre el Empleo Juvenil, publicada en Bruselas a fecha de 24 de mayo del 2013 (http://www. european-council.europa.eu/the-president). Y European Council -27/28 june 2013 -Factsheet on youth employment (http://www.consilium.europea.eu).

${ }^{8}$ Ver Carta del Presidente Herman Van Rompuy a los miembros del Consejo Europeo sobre el Empleo Juvenil.

${ }_{9}^{9}$ Publicado en Bruselas a 3 de marzo del 2010, COM (2010) 2020 final.

${ }^{10}$ Los objetivos que marca el ISI son representativos de las tres prioridades de crecimiento inteligente, sostenible e integrador, pero no son exhaustivos, pues precisan de una amplia gama de acciones a nivel nacional, comunitario e internacional para sustentarlos. Véase páginas 5 y 6 del texto publicado por la Comisión Europea (http://eur-lex.europa.eu/LexUriServ/ LexUriServ.do?uri=COM:2010:2020:FIN:ES:PDF).Entre las siete iniciativas que propone la Comisión destacan en materia de empleo juvenil las siguientes: 1) "Unión por la innovación"; 2) "Juventud en movimiento"; 3) "Agenda de nuevas cualificaciones y empleos" y 4) "La plataforma europea contra la pobreza". Para poder hacer llegar esta información, en la UE se adoptarán directrices y se harán recomendaciones específicas a los Estados miembros, pudiendo la Comisión hacer propuestas para orientar la acción y promover las iniciativas comunitarias.

${ }^{11}$ En esta Estrategia ISI la UE define el lugar que quiere ocupar en 2020, para ello se fija como reto a conseguir para entonces: 1) un incremento del $75 \%$ del empleo entre la población de entre 20 a 64 años, mediante, entre otras cosas, una mayor participación de las mujeres y los trabajadores más mayores, y una integración de los inmigrantes en la población activa; 2) el porcentaje de abandono escolar debe ser inferior al $10 \%$; y 3 ) se pretende que al menos el $40 \%$ de la generación más joven haya cubierto su nivel de estudios universitarios o de Formación Profesional (FP). Véase en este sentido "la Agenda de nuevas cualificaciones y empleos" de 23 de noviembre de 2010. 
sociales e instituciones europeas para obtener ese triunfo.

La alarmante e inaceptable cifra de jóvenes (O'HIGGINS, 2001, p. 11) $)^{12}$ desempleados debe paliarse gracias al establecimiento tanto a escala nacional, como regional de la UE de un catálogo de iniciativas comunitarias, entre las que destacan: 1) "Juventud en movimiento"13 (de 15 de septiembre de 2010); 2) "Unión por la innovación" ${ }^{14}$ (publicado el 6 de octubre de 2010); 3) "Agenda de nuevas cualificaciones y empleos"15 (23 de noviembre de 2010); y 4) "Oportunidades para la juventud" ${ }^{16}$ (20 de diciembre de 2011).

${ }^{12}$ Según la definición que ofrecen las Naciones Unidas de “juventud”, ésta comprende desde los 15 a los 24 años de edad. Sin embargo en la práctica, la definición operativa de gente joven varía ampliamente de un país a otro, dependiendo de factores culturales, institucionales y políticos.

${ }^{13}$ En líneas generales se busca aquí: 1) mejorar los programas de movilidad, universidad e investigación (como Erasmus, Erasmus Mundus, Tempus y Marie Curie) y ligarlos a los programas y recursos nacionales; 2) modernizar la educación superior, incluyendo la evaluación comparativa de los resultados de las universidades y de los sistemas educativos en un contexto general; 3) explorar nuevas formas de promover el espíritu emprendedor mediante programas de movilidad para jóvenes profesionales; 4) promover el reconocimiento del aprendizaje no formal e informal; y 5) lanzar un Marco de Empleo de los Jóvenes que subraye las políticas destinadas a reducir la tasa de desempleo de los jóvenes. Véase la Comunicación de la Comisión al Parlamento Europeo, a la Comisión, al Comité Económica y Social Europeo, y al Comités de las Regiones de 15 de septiembre de 2010 -Juventud en movimiento- Una iniciativa destinada a impulsar el potencial de los jóvenes para lograr un crecimiento inteligente, sostenibles e integrador en la UE, COM (2010) 477 final.

${ }^{14}$ Entre sus objetivos llama muy especialmente la atención: a) la racionalización de los mecanismos administrativos para facilitar el acceso a la financiación por parte de las PYMES, mejorando el entorno empresarial mediante contrataciones públicas que incentiven la innovación; b) la promoción de la cooperación de conocimientos y reforzar los vínculos entre educación, empresa, investigación e innovación; y c) del espíritu emprendedor por medio del apoyo a jóvenes empresas innovadoras. Ver el documento: Una "Unión por la innovación": convertir las ideas en empleo, crecimiento ecológico y progreso social, publicado en Bruselas, IP/10/1288.

${ }^{15}$ Se desea aquí modernizar los mercados laborales y potenciar la autonomía de las personas mediante el desarrollo de capacidades a lo largo de su vida con el fin de aumentar la participación laboral y adecuar mejor la oferta y demanda de trabajos, en particular mediante la movilidad laboral. Véase la Comunicación de la Comisión al Parlamento Europeo, a la Comisión, al Comité Económica y Social Europeo, y al Comités de las Regiones -Agenda de nuevas cualificaciones y empleos: una contribución europea hacia el pleno empleo- publicada en Estrasburgo, COM (2010) 682 final.

${ }^{16}$ Básicamente persigue: 1) facilitar el desarrollo de capacidades y apoyar la transición de la educación al trabajo; b) apoyar la movilidad en el mercado laboral, y 3) reforzar la aplicación de políticas en el marco. Ver Comunicación de la Comisión al Parlamento Europeo, a la Comisión, al Comité Económica y Social Europeo, y al Comités de las Regiones sobre 
Todas estas declaraciones de buenas intenciones deberán estar plenamente interconectadas para garantizar que los jóvenes adquieran la formación necesaria que demanda el mercado, facilitando además su inserción laboral. Siendo, a tal fin, imprescindible que los Estados amplíen la inversión pública destinada a educación y formación, dirigiéndose de forma adecuada para lograr la máxima rentabilidad (HERNÁNDEZ BERAJANO, 2013, p. 283 Y 284). No obstante, para que puedan ponerse en marcha estos programas la Comisión reclama que el Consejo de Europa apoye este inicial plan marco. Se espera pues que éste último concrete, a la mayor brevedad posible, los detalles de la Estrategia incluyendo las directrices integradas y los objetivos nacionales.

La respuesta del Consejo de Europa se hace esperar, llegando finalmente a ver la luz en la cumbre de 27 y 28 de junio de 2013. Efectivamente, tal y como reconoce abiertamente el Consejo, la lucha contra el desempleo juvenil debe ocupar un papel prioritario en el programa a desarrollar por la UE. Se trata de un problema que afecta con especial intensidad a millones de jóvenes en la Eurozona y que está causando gravísimas repercusiones en el desarrollo de estas generaciones (MONEREO PÉREZ, 2009, p. 116) $)^{17}$, por no hablar de las consecuencias que a largo plazo va tener en el campo de la Seguridad Social (empobrecimiento y debilitamiento de las prestaciones, alargamiento de la edad de jubilación, disminución de los niveles de cotización a causa de la rotación en el empleo a tiempo parcial y/o temporal y el disfrute del subsidio por desempleo...etcétera).

Principalmente, el enfoque global de choque contra el desempleo juvenil se sustenta en las siguientes medidas: 1) aceleración de la Iniciativa sobre Empleo Juvenil (hasta un total de 6.000 millones de euros) y concentración del esfuerzo al comienzo del periodo $2014^{18}$; 2) aceleración en la ejecución de la Garantía Juvenil; 3) aumento de la movilidad juvenil ${ }^{19}$; y 4) participación de los interlocutores sociales.

la "Iniciativa de oportunidades para la juventud", publicado en Bruselas a fecha de 20 de diciembre de 2011, $\operatorname{COM}(2011) 933$ final.

${ }^{17}$ Cuanta más tarde es la incorporación al mercado de trabajo, más se retrasa la proyección de un futuro plan de vida familiar, debiendo los jóvenes convivir con sus progenitores hasta que consigan un empleo estable que les permita vivir dignamente $\mathrm{y}$ de forma independiente.

${ }^{18}$ Este plan de estar preparado para su puesta en funcionamiento en enero de 2014, debiendo ejecutarse entre 2014 y 2015, en lugar de distribuirlo entre el periodo 2014 a 2020 tal y como preveía la Estrategia Europa 2020 (ISI).

${ }^{19}$ Se está trabajando para impulsar la movilidad de los jóvenes solicitantes de empleo, por medio del refuerzo del programa "tu primer trabajo EURES" (your first EURES job). Para lo cual los Estados miembros podrán hacer uso de parte de las asignaciones que destine el Fondo Social Europeo (FSE) para el apoyo de los regímenes de movilidad transfronteriza. En este sentido, y de igual modo, el programa 
Con vistas a lograr los mejores resultados, la UE pone a disposición de aquellos Estados con una tasa de desempleo juvenil superior al 25\% (entre los que se encuentra España, Portugal, Grecia, Italia, Francia y Eslovenia) los fondos comunitarios (especialmente los del FSE y otros instrumentos de cohesión provenientes de la reprogramación de fondos estructurales sin gastar) destinados a la creación de empleo, formación profesional y prevención del abandono escolar, reforzando así la nueva iniciativa sobre el Empleo juvenil (2014-2020) ${ }^{20}$. Los Estados miembros que sean beneficiarios de la Iniciativa sobre Empleo Juvenil deberán adoptar un plan para abordar el paro de los jóvenes, en particular, mediante la aplicación de la "Garantía Juvenil". De este modo, se evitará que ningún joven de hasta 25 años se quede más de cuatro meses sin trabajo, formación o periodo de prácticas (SUÁREZ CORUJO, 2014, p. 87 ${ }^{21}$. Asimismo, el Banco Europeo de Inversiones (BEI) contribuirá también en la lucha contra el desempleo a través de su iniciativa "Trabajo para jóvenes" y su programa "Inversión en la Capacitación".

Finalmente, destaca la puesta en marcha de un nuevo "Plan de Inversiones" para fomentar el crecimiento y el empleo gracias al apoyo financiero de las PYME. Y es que, resulta fundamental potenciar el emprendimiento y el trabajo por cuenta propia ${ }^{22}$, como se verá a continuación en el siguiente apartado.

\section{El establecimiento de UN MARCo JURÍdico-POLÍtico PARA EL CRECIMIEN- TO DEL EMPLEO JUVENIL EN ESPAÑA: LA LEY DE EMPRENDEDORES}

\subsection{Plan de medidas de políticas de empleo en España}

De conformidad con el marco jurídico que establece la actual Ley 56/2003, de 16 de diciembre, de Empleo (BOE núm. 301 de 17 de diciembre de 2003): "La política de empleo (en España) se desarrollará, dentro de las orientaciones gene-

"Erasmus+", deberá estar plenamente operativo a partir de enero del 2014.

${ }^{20}$ De los 6.000 millones de euros que la UE destina para la lucha contra el desempleo juvenil, España recibirá: a) 918 millones de euros, procedentes de la partida presupuestaria específica para Empleo juvenil y b) 932 millones de euros, procedentes del FSE.

${ }^{21}$ En aras de acceder a estos fondos de financiación, el Gobierno español ha enviado a la Comisión Europea, en diciembre de 2013, el "Plan Nacional de Implantación de la Garantía Juvenil en España". En este documento se recogen, entre otros, los mecanismos de instrumentación de la "Garantía Juvenil" en nuestro país a través de las medidas de mejora de la intermediación, la empleabilidad, el emprendimiento y la contratación.

${ }^{22}$ Véase las conclusiones del Consejo de Europa de 27 y 28 de junio del 2013 (EUCO 104/2/13 REV 2), páginas: 3 a 5. 
rales de la politica económica, en el ámbito de la estrategia coordinada para el empleo regulada por el Tratado Constitutivo de la Comunidad Europea" (artículo 1.1). Por lo que, desde un primer momento, se deja claro que la política de empleo nacional queda condicionada a lo dispuesto por la política de integración europea (MONEREO PÉREZ, 2009, p. 6-49).

Haciendo gala del ejercicio de competencias que se atribuyen por el art. 3.1 de la Ley del Empleo, se publica en 2011 la Estrategia Española de Empleo 2012$2014^{23}$. Normativa que ha constituido desde entonces el nuevo paradigma estratégico de las políticas de empleo que se han de fijar en nuestro territorio (con carácter general) a través del Sistema Nacional de Empleo, señalando para ello, una serie de metas (tanto de carácter económico, como político) y acciones a alcanzar a corto plazo ${ }^{24}$.

El fin último que se pretende no es otro que el de: "fomentar el empleo de la población activa y aumentar la participación de hombres y mujeres en el mercado de trabajo, mejorando la productividad y la calidad en el empleo en un mercado de trabajo sostenible, basado en la igualdad de oportunidades, la cohesión social y territorial"25. O dicho en otras palabras, de lo que se trata es de hacer justicia al tenor literal del art. 35.1 de la Constitución Española (CE), esto es, al "derecho al trabajo" (MONEREO PÉREZ, 2009, p. 9-12) ${ }^{26}$, en armonía con lo previsto por el art. 40.1 del mismo cuerpo legal: "los poderes públicos promoverán las condiciones favorables para el progreso social y económico y para una distribución de la renta regional y personal más equitativa, en el marco de una política de estabilidad económica. De manera especial realizarán una política

\footnotetext{
${ }^{23}$ Aprobada como Real Decreto 1542/2011, de 31 de octubre por el que se aprueba la Estrategia Española de Empleo 2012-2014 (BOE núm. 279, de 19 de noviembre de 2011). Normativa que se inserta dentro del Plan Nacional de Reformas.

${ }^{24}$ En particular, se determinan seis objetivos de política de empleo: 1) elevación de la tasa de empleo al 74\% para la población de entre 30-64 años en el horizonte de 2020, con un sub-objetivo de tasa de empleo femenino para el mismo grupo de edad del $68,5 \%$; 2 ) reducir la temporalidad y la segmentación del mercado de trabajo; 3 ) reforzar el trabajo a tiempo parcial y la flexibilidad interna de las empresas; 4) mejorar y adecuar las competencias profesionales a las necesidades del mercado; 5) promover una rápida y adecuada reinserción de las personas en el mercado laboral; y 6) promover la igualdad de género en el mercado.

${ }^{25}$ Véase apartado 3.1 "La estrategia española de empleo 2012-2014 y la estrategia Europa 2020", página: 22 del texto legal.

${ }^{26}$ Como bien señala el profesor J.L Monereo Pérez, de lo que se trata es de garantizar “.... la protección de la persona del trabajador en el empleo y en el mercado de trabajo..., pero también fuera o al margen del mercado de trabajo a través de las políticas de protección de Seguridad Social por desempleo".
} 
orientada al pleno empleo"; y lo dispuesto por el artículo 14 de la $\mathrm{CE}^{27}$. Ahora bien, no será posible la consecución de dicha meta, si antes no se han asentado las bases para la confección de los instrumentos jurídicos que van a servir de orientación a las políticas públicas hacia la obtención de un empleo estable, de calidad y que asegure plenas garantías laborales a todos los trabajadores ${ }^{28}$.

Para la Estrategia Española, la cualificación e inserción laboral de los jóvenes se alza en un plano preferente. No obstante, teniendo en cuenta la heterogeneidad de edades, se han previsto distintas acciones dependiendo de la etapa y el nivel de formación en la que este colectivo se encuentre ${ }^{29}$. Asimismo, se impulsa el empleo del contrato para la formación y el aprendizaje como doble vía para la inserción laboral y la formación ${ }^{30}$.

${ }^{27}$ En esta línea, no debemos olvidar la previsión recogida en los arts. 21 y 23 de la Carta de los Derechos Fundamentales de la UE. Así pues, mientras que el primero de ellos versa sobre el principio de no discriminación por razón de sexo, el segundo, evoca el principio de igualdad entre mujeres y hombres. Para un análisis más exhaustivo en esta materia, véase los estudios que realiza la profesora C. Monereo Atienza a dichos preceptos en VV.AA, Monereo Atienza, C y Monereo Pérez, J.L: La Europa de los Derechos. Estudio sistemático de la Carta de los Derechos Fundamentales de la Unión Europea, Granada, Comares, 2012, páginas: 463-480 y 503-529.De igual modo, debe tenerse presente lo dispuesto por la Directiva 2000/78/CE del Consejo, de 27 de noviembre del 2000, relativa al establecimiento de un marco general para la igualdad de trato en el empleo y la ocupación (EUR-32000L0078) $\mathrm{y}$ en concreto, sus artículos 2 (en donde se propugna el principio de igualdad de trato entre mujeres y hombres) y 25 ("La prohibición de discriminación por razones de edad constituye un elemento fundamental para alcanzar los objetivos establecidos por las directrices sobre el empleo y para fomentar la diversidad en el mismo"). Téngase en cuenta también la sentencia del Tribunal de Justicia de la Unión Europea, de 21 de julio de 2011 (TJCE/2011/277), en donde se realiza una interpretación de las circunstancias que pueden dar lugar a llevar a cabo diferencias de trato por motivos de edad.

${ }^{28}$ Punto en el que también insiste la Comisión Europea al hablar de la necesidad de elaborar un marco de calidad para evitar que se utilice a los jóvenes como mano de obra barata y gratuita, fomentando así una espiral viciosa de empleo precario. A este respecto, hacen saltar las alarmas de la UE acerca de las condiciones en las que trabajan muchos jóvenes en Europa, los hechos ocurridos a fecha de 20 de agosto de 2013 en la ciudad de Londres, lugar en donde muere un becario del Bank of América de 21 años tras estar 72 horas seguidas trabajando (http://www.thetimes.co.uk/tto/news/uk/article3848066.ece).

${ }^{29}$ Para los jóvenes menores de 20 años no titulados, las medidas se focalizan hacia la reincorporación al sistema educativo, de la misma manera que para aquellos con edades comprendidas entre 20 y 25 años.

${ }^{30}$ Véase también el Real Decreto 1529/2012, de 8 de noviembre, por el que se desarrolla el contrato para la formación y el aprendizaje y se establecen las bases de la formación profesional dual (BOE núm. 270 de 9 de noviembre de 2012). 
Tanto los poderes públicos, como los agentes sociales están preocupados por la situación económica y política del empleo juvenil. Así pues, como se refleja en el siguiente gráfico, la tasa de desempleo juvenil en España ha aumentado considerablemente en los últimos años hasta situarse en un 53,1\% en los menores de 25 años:

España: Paro menores de 25 años 2014

\begin{tabular}{|r|r|r|r|}
\hline \multicolumn{1}{|c|}{ Periodo } & $\begin{array}{r}\text { Paro menores de 25 } \\
\text { años (ambos sexos) }\end{array}$ & $\begin{array}{r}\text { Paro hombres me- } \\
\text { nores de 25 }\end{array}$ & $\begin{array}{c}\text { Paro mujeres } \\
\text { menores de 25 }\end{array}$ \\
\hline Junio 2014 & $53,1 \%$ & $53,8 \%$ & $52,4 \%$ \\
Marzo & $55,5 \%$ & $56,0 \%$ & $54,9 \%$ \\
2014 & $54,9 \%$ & & \\
Diciembre & $54,1 \%$ & $55,6 \%$ & $54,1 \%$ \\
2013 & & $54,0 \%$ & $54,4 \%$ \\
Septiembre & 5 & & \\
2013 & & & \\
\hline
\end{tabular}

Gráfica 1. Elaborada por el INE tras un estudio trimestral de la situación del mercado de trabajo en los jóvenes menores de 25 años.

A la vista de estos resultados, el Gobierno Español ha elaborado un elenco de medidas para favorecer la participación laboral de este grupo, evitando así un incremento del desempleo juvenil y potenciando además el crecimiento de la actividad económica que permita crear empleo. Son muestra de todo ello, por matizar en algunas de estas iniciativas: 1) la Resolución de 30 de enero de 2012, de la Dirección General de Empleo, por la que se registra y publica el II Acuerdo para el Empleo y la Negociación Colectiva 2012, 2013 y 2014 ${ }^{31}$; 2) el Acuerdo para el progreso económico y social de Andalucía ${ }^{32}$; 3) la Resolución de 28 de agosto de 2013, de la Secretaría de Estado de Empleo, por la que se publica el Acuerdo del Consejo de Ministros de 2 de agosto de 2013, por el que se aprueba el Plan Anual de Política de Empleo para $2013^{33}$. Para esta última se han contemplado un listado de acciones y/o medidas a ejecutar, entre las que se encuentra la de "mejora de la empleabilidad de los jóvenes

\footnotetext{
${ }^{31}$ BOE núm. 31 de 6 de febrero de 2012. Acuerdo subscrito a fecha de 25 de enero del 2012, de una parte, por la Confederación Española de Organizaciones Empresariales (CEOE) y la Confederación Española de la Pequeña y Mediana Empresa (CEPYME) y, de otra parte, por las Confederaciones Sindicales de CCOO y UGT.

${ }^{32}$ Firmado a fecha de 20 de marzo del 2013 por UGT, CCOO y la Confederación de Empresarios de Andalucía (CEA). Tienen como destinatarios preferentes, entre otros, a las personas jóvenes menores de 35 años.
}

${ }^{33}$ BOE núm. 217 de 10 de septiembre de 2013. 
y el apoyo al emprendimiento"34. Regla, que si bien, se encuentran en la misma línea que las de aquellas otras que recoge la Ley 3/2012, de 6 de agosto de medidas urgentes para la reforma del mercado laboral: 1) como fomento de la empleabilidad; 2) garantía del empleo y de la contratación indefinida; y 3) facilitación del autoempleo. Concretamente, sobre estas últimas se enmarcan las actuales estrategias de fomento y apoyo al emprendimiento.

\subsection{LAS LEYES DE MEDIDA Y APOYO AL EMPRENDIMIENTO}

Para recuperar la senda del crecimiento económico y de creación empleo en nuestra nación resultará necesario que el Gobierno continúe con el esfuerzo reformista, pero en el sentido autentico de una reforma propia de un Estado social y democrático de derecho. Para ello las estrategias de empleo juvenil habrán de estar orientadas a la consecución del pleno empleo, es decir, a la obtención de un trabajo decente, digno y de calidad en el marco de un modelo de política de competitividad por innovación y conocimiento, que rechace frontalmente el modelo neoliberal de política de competitividad por reducción de costes y precarización del trabajo. A tal fin todas las miradas se centran en aumentar la calidad y estabilidad de los jóvenes en el empleo a través de los sistemas de inserción laboral que se proponen en la ley de emprendedores.

Recientemente, a nivel nacional se han publicado dos importantes normas en esta materia (las cuales podrán ser aplicables tanto para el ámbito de la empresa privada, como para el caso de que la contratación se realice en el sector público), de un lado la Ley 11/2013, de 26 de julio de medidas de apoyo al emprendedor y de estímulo del crecimiento y de la creación de empleo ${ }^{35}$; y de otro lado la Ley 14/2013, de 27 de septiembre, de apoyo a los emprendedores y a su internalización ${ }^{36}$. A ni-

34 Junto a esta se encuentran también: a) la mejora de la empleabilidad de otros colectivos especialmente afectados por el desempleo; b) la mejora de la calidad de la formación profesional en el empleo y; 3 ) la mejora de la vinculación de las políticas activas y pasivas de empleo. Véase apartado 5 "Estructura y objetivos" de esta resolución.

${ }^{35}$ BOE núm. 179, de 27 de julio del 2013. Previamente a esta, sale a la luz el Real Decreto, de 22 de febrero, de medidas de apoyo al emprendedor y de estímulo del crecimiento y de la creación de empleo (BOE núm. 47, de 23 de febrero de 2013). Normativa que trata de dar respuesta y se inserta entre las medidas que el Ministerio de Empleo y Seguridad Social están llevando a cabo, dentro de la llamada "Estrategia de Emprendimiento y Empleo Joven 2013-2016".

36 BOE núm. 233, de 28 de septiembre de 2013. Esta última normativa ha sido objeto de aclaración por la Junta Consultiva de Contratación Administrativa Estatal a la vista de las dudas interpretativas que le han surgido a una pluralidad de órganos de contratación del Sector Público desde su entrada en vigor. Recordemos que esta Ley 14/2013, de 27 de septiembre, modifica algunos preceptos de la Ley de Contratos del Sector Público (Real Decreto Legislativo 3/2011, de 14 de noviembre, por el que se aprueba el Texto Refundido de la Ley 
vel andaluz, con motivo del reparto de competencias entre Estado y Comunidades Autónomas (CCAA), nace el Decreto-Ley de 8/2013 de 28 de mayo, de Medidas de Creación de Empleo y Fomento del Emprendimiento ${ }^{37}$, convalidado a fecha de 28 de junio del 2013 por Resolución de la Presidencia del Parlamento de Andalucía ${ }^{38}$. De igual modo, en el resto de CCAA se han creado y publicado también leyes de emprendedores como respuesta a esa iniciativa nacional para el fomento del empleo juvenil ${ }^{39}$.

de Contratos del Sector Público -BOE núm. 276 de 16 de noviembre de 2011-), entre los que cabe destacar el art. 146. Para un conocimiento más exhaustivo en esta materia véase la Recomendación de 26 de noviembre de 2013 (JUR/2013/356789).

${ }^{37}$ BOJA núm. 105, de 31 de mayo del 2013.

${ }^{38}$ BOJA núm. 133, de 10 de julio de 2013.

${ }^{39}$ A saber: Ley núm. 2/2012, de 4 de abril de apoyo a los emprendedores y las emprendedoras y a la micro, pequeña y mediana empresa en la Comunidad Autónoma de las Islas Baleares (BOE no 105 de 2 de mayo de 2012); La ley núm. 16/2012, de 28 de junio de Apoyo a las Personas Emprendedoras y a la Pequeña Empresa del País Vasco (Boletín Oficial del País Vasco $\mathrm{n}^{\circ} 132$ de 6 de julio de 2012); Decreto núm. 97/2012, de 19 de julio, por el que se establece en el marco del emprendimiento, las bases reguladoras de subvenciones relativas al Plan de fomento al emprendedor autónomo y Pyme destinadas a la iniciativa de autoempleo en Castilla-La Mancha (LCLM 2012/167); Orden núm. 2680/2012, de 26 de diciembre, de la Consejería de Empleo, Turismo y Cultura, por la que se establecen las bases reguladoras para la compensación de cuotas a la Seguridad Social a aquellos emprendedores que creen empleo o prorroguen la duración de los contratos ya existentes, y se convocan subvenciones para el año 2012 (BOCM de 13 de noviembre de 2012); Ley Foral núm. 12/2013, de 12 de marzo, de apoyo a los emprendedores y al trabajo autónomo en Navarra (BOE n ${ }^{\circ} 83$ de 6 de abril de 2013); Ley núm. 5/2013, de 19 de junio, de Estímulo a la Creación de Empresas en Castilla y León (BOE n ${ }^{\circ} 168$ de 15 de julio de 2013); Ley núm. 5/2013, de 8 de julio, de apoyo a los emprendedores y a la competitividad e internacionalización de las pequeñas y medianas empresas (PYMES) de la Región de Murcia (Boletín Oficial de la Región de Murcia n ${ }^{\circ} 158$ de 10 de julio de 2013); Ley núm. 10/2013, de 21 de octubre, de apoyo a emprendedores, autónomos y Pymes en La Rioja (BOE n⿳ 268 de 8 de noviembre de 2013); Ley núm. 6/2013, de 6 de noviembre, de Cooperativas de Cantabria (BOE n 284 de 27 de noviembre de 2013); Decreto núm. 245/2013, de 30 de diciembre, por el que se modifica el Decreto213/2012, de 19 de octubre, por el que se establecen las bases reguladoras del programa de ayudas para el fomento de la investigación, el desarrollo tecnológico y la innovación en la actividad emprendedora y empresarial de las pequeñas, medianas y grandes empresas en el ámbito de la Comunidad Autónoma de Extremadura (DOE n 5 de 9 de enero de 2014); Decreto núm. 36/2014, de 14 de marzo, de Gobierno de Aragón por el que se modifica el Decreto 111/2012, de 24 de abril por el que se aprueba el Programa de Emprendedores y se establecen las bases reguladoras para la concesión de las subvenciones contempladas en el mismo para la promoción del empleo de aquellos emprendedores que se establezcan como trabajadores autónomos o constituyan microempresas en la Comunidad Autónoma de Aragón (Boletín Oficial de Aragón n ${ }^{\circ} 155$ de 19 de marzo de 2014); Orden núm. EMO/114/2014, de 4 de abril, por la 
Sin embargo, antes de entrar en el análisis de cada una de las leyes de emprendedores, cabe aludir al "contrato indefinido de apoyo a emprendedores" que recoge el art. 4 de la Ley 3/2012, de 6 de agosto de medidas urgentes para la reforma del mercado laboral. Gracias a esta normativa nace en nuestro sistema iuslaboralista un nuevo contrato que, deroga al antiguo "contrato de fomento del empleo estable", pero que, al igual que hacía su precedente, se dirige, entre otros, a jóvenes entre 16 y 30 años ${ }^{40}$. Entre los estímulos que este contrato ofrece para facilitar el empleo estable aparece, de un lado, una serie de deducciones fiscales -art. 43 del Texto Refundido de la Ley de Impuesto sobre Sociedades, aprobado por Real Decreto Legislativo

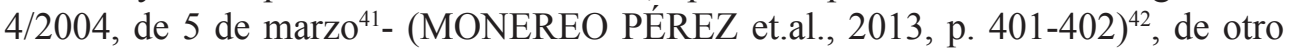
lado, bonificaciones a cargo del Servicio Público de Empleo Estatal y, finalmente, reducciones de las cuotas sociales durante un periodo de tres años, siendo su cuantía variable dependiendo del colectivo laboral al que se dirija ${ }^{43}$. Las empresas de menos

que se aprueban las bases reguladoras de la línea de ayudas en forma de garantía para la financiación empresarial de proyectos de autónomos, micro, pequeñas y medianas empresas, y se hace pública la correspondiente convocatoria para la Línea de emprendedores, autónomos y comercios para el año 2014 en Cataluña (DOGC núm. 6604 de 15 de Abril de 2014); Orden de 30 de mayo de 2014, por la que se establecen las bases reguladoras del Programa de las iniciativas emprendedoras y de empleo $(\mathrm{I}+\mathrm{E}+\mathrm{E})$, cofinanciado por el Fondo Social Europeo, y se procede a su convocatoria para el año 2014 (DOG n 110 de 11 de junio de 2014); Ley núm. 5/2014, de 25 de julio, de Fomento y Consolidación del Emprendimiento, el Trabajo Autónomo y las Pymes en la Comunidad Autónoma de Canarias (Boletín Oficial de Canarias $\mathrm{n}^{\mathrm{o}} 152$ de 7 de agosto de 2014).

${ }^{40} \mathrm{Y}$ a mayores de 45 años.

${ }^{41}$ BOE núm. 61 de 11 de Marzo de 2004.

${ }^{42}$ Estas deducciones serán de 3000 Euros para la contratación del primer trabajador de la empresa cuando sea menor de 30 años, de una parte, y del 50\% de una de las cantidades variables atendiendo a la cuantía de prestación que le reste por percibir si se contrata a perceptores de prestaciones por desempleo del nivel contributivo. En este caso, se podrá compatibilizar la prestación por desempleo y el salario hasta un máximo del $25 \%$ de aquélla.

${ }^{43}$ Véase el art. 4.5 de la Ley 3/2012: ... a) Jóvenes entre 16 y 30 años, ambos inclusive, la empresa tendrá derecho a una bonificación en la cuota empresarial a la Seguridad Social durante tres años, cuya cuantía será de 83,33 euros/mes (1.000 euros/año) en el primer año; de 91,67 euros/mes (1.100 euros/año) en el segundo año, y de 100 euros/mes (1.200 euros/ año) en el tercer año.Cuando estos contratos se concierten con mujeres en ocupaciones en las que este colectivo esté menos representado las cuantías anteriores se incrementarán en 8,33 euros/mes (100 euros/año).b) Mayores de 45 años, la empresa tendrá derecho a una bonificación en la cuota empresarial a la Seguridad Social, cuya cuantía será de 108,33 euros/ mes (1.300 euros/año) durante tres años. Cuando estos contratos se concierten con mujeres en ocupaciones en las que este colectivo esté menos representado, las bonificaciones indicadas serán de 125 euros/mes (1.500 euros/año).Estas bonificaciones serán compatibles con otras ayudas públicas previstas con la misma finalidad, sin que en ningún caso la suma de 
de 50 trabajadores podrán recurrir a esta modalidad de contrato mientras la tasa de desempleo sea superior al 15\%, no perdiendo los incentivos indicados siempre que el trabajador se mantenga en su puesto de trabajo al menos durante tres años (tras la superación del periodo de prueba de 1 año).

Actualmente, el "contrato indefinido de apoyo a emprendedores" constituye una de las figuras más criticadas tanto por la doctrina, como por la jurisprudencia. Y ello es porque por ley se ha fijado, como condición sine qua non, un período de prueba de 365 días para que el trabajador pueda acceder a la contratación indefinida $\mathrm{y}$, por consiguiente, pueda la empresa disfrutar de todo ese conjunto de beneficios fiscales y de Seguridad Social (hasta un periodo máximo de tres años, contados a partir de la superación del periodo de prueba) $)^{44}$. Ciertamente, en momentos de crisis económica se deben adoptar medidas coyunturales para potenciar el empleo estable, ahora bien, entiendo que ello no debe conllevar la disminución de derechos en los trabajadores. La praxis ordinaria está demostrando como por obra de ese periodo de prueba tan dilatado en el tiempo ( 1 año) se ha abierto la puerta a que los empresarios desistan de los contratos celebrados, antes de la terminación del periodo de prueba, creando así un círculo vicioso en donde los trabajadores (previamente contratados) son despedidos y sustituidos por segundos trabajadores, de cuyos contratos nuevamente desistirá el empresario y así sucesivamente ${ }^{45}$. Los temas centrales en los que se centra este intenso debate se sitúa en torno a estas tres cuestiones: 1) la naturaleza jurídica del periodo de prueba y si en caso de desistimiento constituiría éste un despido ad nutum $^{46}$; 2) la necesidad o no de alegar una causa para proceder al desisti-

las bonificaciones aplicables pueda superar el $100 \%$ de la cuota empresarial a la Seguridad Social.En el supuesto de que el contrato se celebre a tiempo parcial, las bonificaciones se disfrutarán de modo proporcional a la jornada de trabajo pactada en el contrato.

${ }^{44}$ Para un conocimiento más completo véase, MONEREO PÉREZ, J.L: "Nuevos contenidos de la Negociación Colectiva y límites legales de los mismos, con particular atención a la jubilación obligatoria y al periodo de prueba", Temas Laborales, monográficos sobre los efectos de la reforma laboral en la negociación colectiva, $\mathrm{n}^{\circ} 120,2013$, páginas 439 y siguiente, en particular, páginas 473 y 477.

${ }^{45}$ Véase, a este respecto, la STC de 17 de julio de 2014, en donde tan sólo el voto particular que formula el Magistrado don Fernando Valdés Dal-Ré a esta sentencia con recurso inconstitucionalidad núm. 5603-2012 (y al que se adhiere la Magistrada Doña Adela Asua Batarrita y el Magistrado Don Luis Ignacio Ortega Álvarez) camina en esta misma línea (Apartado III, punto 5 del voto particular)).

${ }^{46}$ Argumenta la opinión mayoritaria del TC en su sentencia de 17 de julio de 2014 que: “... el desistimiento durante el periodo de prueba no constituye un despido, sino la plasmación, a través de una declaración de voluntad, de una condición resolutiva, positiva y potestativa, expresamente asumida por las partes en el momento de suscripción del contrato. Es cierto que la posibilidad legal de introducir en el contrato tal condición resolutiva (...) constituye un mecanismo que habilita la extinción contractual ad nutum a iniciativa empresarial. Desde esta perspectiva, por tanto, el periodo de prueba admitido y regulado por el legislador puede 
miento del trabajador ${ }^{47}$ y el derecho a una indemnización ${ }^{48}$ y 3) la razonabilidad o

actuar como una limitación del derecho a la estabilidad en el empleo (...) y que, por tal razón, entra en conexión con el art. 35.1 Constitución Española...”.

${ }^{47}$ En este punto argumenta la tesis mayoritaria del Constitucional que: “... el legislador ha optado, como regla general, por admitir en las relaciones laborales la posibilidad de pactar un periodo de prueba, durante cuyo transcurso, cualquiera de las partes -incluido el empresariopuede proceder a la resolución contractual. De este modo la admisión normativa de dicha estipulación se configura como una excepción al carácter causal que el ordenamiento legal, también como regla general, exige a las extinciones contractuales a iniciativa empresarial; sin perjuicio, claro está, de que, como este Tribunal ha reiterado, la motivación de la decisión extintiva se encuentre limitada por el necesario respecto a los derechos fundamentales y el principio de no discriminación" (Véase el Fundamento Jurídico $\mathrm{n}^{\circ} 3$ en su apartado c). Por el contrario, el voto particular a esta sentencia de 17 de julio de 2014 sostiene que "... las resoluciones impugnadas... aparece reforzadas por el hecho de que tanto exigencias constitucionales, como compromisos internacionales, hacen que rijan entre nosotros el principio general de la limitación legal del despido, así como su sujeción para su licitud a condición de fondo y forma. (...) No debe olvidarse... que, en su vertiente individual, el derecho al trabajo (art. 35.1 CE) se concreta en el derecho a la continuidad o estabilidad en el empleo, es decir, en el derecho a no ser despedido sin justa causa. (...) la desregulación de las dos grandes modalidades de despido (por incumplimiento del trabajador de los deberes contractuales y por razones relacionadas con el funcionamiento de la empresa) resultaría de todo punto incompatibles con el art. 35.1 CE, de modo que queda proscrito, por mandato constitucional, el establecimiento de extinciones ad nutum... pues la medida afectaría al contenido esencial del derecho al trabajo (Ver apartado III, punto 2 de este voto particular). En el ámbito comunitario, el reconocimiento expreso del derecho "de todo trabajador a una protección en caso de despido injustificado" se encuentra expresamente reconocido en el art. 30 de la Carta de Derechos Fundamentales de la Unión Europea del año 2009 (Carta de Niza), incorporada al Tratado de la Unión... Esta incorporación ha tenido el efecto de reforzar notablemente el carácter causal del despido y la necesidad de adoptar sistemas de "reacción adecuados" contra los ceses empresariales, a fin de evitar el debilitamiento del derecho del trabajo y, a su través, el vaciamiento de su función tuitiva, que ha de entenderse integrada en su código genético (Apartado III, punto 2, letra a) de este voto particular)".

48 Sobre este tema la STC de 17 de julio de 2014 declara la pérdida del derecho a una indemnización cuando el trabajador es despedido sin causa durante el periodo de prueba, lo que priva al trabajador de sus derechos laborales (tal y como sostiene el voto particular que formula el Magistrado Fernando Valdés Dal-Ré). En la misma línea del voto particular a la anterior STC (y, por consiguiente, en contra de lo que sostiene la opinión mayoritaria), la Sentencia del Juzgado de lo Social de Barcelona de 19 de noviembre de 2013 (AS 2013/2802) entiende que el hecho de que la Ley 3/2012 se publique en un momento de crisis económica no puede conllevar dejar desprotegido a los derechos de los trabajadores. De ahí que declare el desistimiento durante el periodo de prueba de un trabajador contratado bajo la fórmula del "contrato indefinido de apoyo a emprendedores" como un despido improcedente. Debiendo el empleador optar por la readmisión del trabajador o el derecho a un indemnización calculada a razón de 45 días de salario por año de servicio (Ver el Fundamento de Derecho Quinto 
no de la duración del periodo de prueba ${ }^{49}$ y los límites que a la negociación colectiva impone la Ley $3 / 2012^{50}$.

de esta sentencia).

49 Defiende el TC, posición mayoritaria, en su Sentencia de 17 de julio de 2014 que: “... la introducción del contrato de trabajo por tiempo indefinido de apoyo a los emprendedores y del régimen jurídico que lo acompaña no constituye sino una nueva actuación del legislador sobre la duración de la contratación laboral y de la estabilidad en el puesto de trabajo. Pretende ofrecer una respuesta que entiende adecuada ante una situación de grave crisis del empleo como la que refleja el preámbulo de la Ley 3/2012, donde se deja constancia de una cifra de paro de 5.273.600 personas. Respecto a la determinación de la duración razonable, la OIT ha afirmado que se trata de un aspecto que corresponde resolver a cada Estado. El límite de duración de tal período lo ha fijado en que no sea "excesivamente largo"(...) Atendido el contexto de grave crisis económica y alto desempleo... hemos de afirmar que la fijación en esta modalidad contractual de un periodo de prueba superior al generalmente previsto para las demás relaciones laborales encuentra justificación; no sólo en la finalidad típica de todo período de prueba sino, sobre todo, en la específica y legítima finalidad de potenciar la iniciativa empresarial como instrumento para contribuir, junto con otras medidas de su régimen jurídico, a promover la creación de empleo establece, de conformidad con el mandato que el art 40.1 CE dirige a los poderes públicos para llevar a cabo una política orientada al pleno empleo (Apartado 3, letra e) de los Fundamentos Jurídicos".Por el contrario, el Magistrado Valdés Dal-Ré considera que: “... un período tan excesivo no es "razonable”, como exige el convenio de la OIT, pues priva al trabajador de lo esencial de sus derechos en materia de despido, colocándolo en una situación comparable a la existente en un momento anterior a la Ley 13 de julio de 1973 en la cual la carga de la prueba del abuso de la ruptura recaía en el trabajador. Y concluyo su razonamiento estimando que esa regresión es contraria a los principios fundamentales del derecho del trabajo, desarrollados por la jurisprudencia y reconocidos por la ley, privando a los trabajadores de las garantías de ejercicio de su derecho al trabajo. (...) Como se desprende de la regulación transcrita, el límite temporal es decisivo para el logro de una adecuada configuración legal del periodo de prueba que garantice el constitucionalmente exigible equilibrio entre los intereses de los empresarios y de los trabajadores. Al formar parte el principio de causalidad del contenido esencial del derecho del trabajo ex art. 35.1 CE, la limitación temporal del periodo de prueba confiere a la suspensión de dicho principio un carácter transitorio, asegurando su activación una vez transcurrido ese plazo. En tal sentido, no estará de más recordar que el Convenio 158 de la OIT autoriza a los Estados a “exceptuar" el régimen causal durante el período de prueba "siempre que la duración se haya fijado de antemano y sea razonable" (art. 2.2 b). El Convenio se constituye así en un canon interpretativo insoslayable" (Apartado III, punto 5)).

${ }^{50}$ Tanto la opinión mayoritaria, como el voto particular a la STC de 17 de julio de 2014 afirman que la previsión que contiene el art. 4.3 de la Ley 3/2012, impone un límite a la negociación colectiva al no permitir que ésta pueda fijar un periodo de duración menor para ese período de prueba. Ahora bien, mientras que la tesis mayoritaria entiende que esta medida resulta razonable dada la situación económica de nuestro país, por el contrario, el voto particular defiende que se está produciendo una intromisión en el derecho a la negociación colectiva, el cual es reconocido en nuestra Carta Magna (Véase STC de 17 de julio de 2014). 
Pasando ya al análisis de las distintas leyes de emprendedores aparece, en primer lugar, la Ley 11/2013 de 26 de julio, la cual se caracteriza, principalmente, por contener una regulación muy heterogénea en la que confluyen todo un elenco de disposiciones de carácter laboral, de Seguridad Social, fiscal, de sector (hidrocarburos, ferroviario...), de lucha contra la morosidad...etc, que modifican diversos preceptos del actual Real Decreto Legislativo 1/1994, de 20 de junio, por el que se aprueba el Texto Refundido de la Ley General de la Seguridad Social (LGSS). En lo referente al ámbito profesional, la normativa busca impulsar un conjunto de medidas orientadas a una doble dirección: a) el autoempleo y emprendimiento, y b) la inserción laboral por cuenta ajena. Haciendo además, partícipes de estas disposiciones tanto a instituciones públicas y privadas, como empresas y organizaciones que deseen colaborar ${ }^{51}$.

Para incentivar el autoempleo de los más jóvenes $\left(1^{\circ}\right.$ bloque de medidas $)$ deberá, previamente, incentivarse a todos los niveles de nuestra sociedad un espíritu emprendedor. Encontrándose a este fin la clave de éxito en la reforma del sistema educativo ${ }^{52}$. En esta línea de pensamiento se presenta, en segundo lugar, la Ley 14/2013, de 27 de septiembre que incorpora ahora en todas las etapas de la Educación Básica (Primaria y Secundaria), Formación Profesional (FP) y Bachillerato; un revolucionario mecanismo que persigue, sin ambages, reforzar las competencias y habilidades necesarias para despertar en los jóvenes ese espíritu emprendedor. Para lo cual el personal docente habrá de adquirir las competencias y habilidades necesarias, a través de la formación inicial y permanente, cumpliendo así de forma eficaz con dicho objetivo. De igual modo las Universidades no pueden quedar exentas, siendo necesarias en ellas la ejecución de tareas de información y asesoramiento para que los estudiantes se inicien en el emprendimiento ${ }^{53}$.

Al margen de estas medidas de las que muchos jóvenes no han podido actualmente beneficiarse, llaman poderosamente la atención, primeramente, un conjunto de reducciones y bonificaciones a la Seguridad Social ${ }^{54}$ que mediante Ley 11/

${ }^{51}$ Véase Preámbulo de la Ley 11/2013, de 26 de julio.

52 En esta línea, VV.AA: Empleo Juvenil en España, Madrid, Ministerio de Trabajo y Asuntos Sociales, 2007, páginas: 55 a 81 .

${ }^{53}$ Véase Título I. "Apoyo a la iniciativa emprendedora”, concretamente en su capítulo I. "Educación en emprendimiento" (artículos 4, 5 y 6). Como consecuencia de ello, el legislador ha encomendado a las administraciones educativas la revisión y adecuación de los currículos de las enseñanzas regladas a estos nuevos fines. Ya en la Universidad de Granada se ha iniciado esta tarea gracias a la apertura de un curso para el fomento de la capacidad emprendedora a través del Centro de Promoción de Empleo y Prácticas (CPEP). A este respecto, puede consultarse el anuncio que realiza el periódico Ideal de Granada a fecha de 29 de octubre de 2013 en su página 12.

${ }^{54}$ Sobre este punto, la Asociación Española de Salud y Seguridad Social (AESSS) ha emitido un comunicado, con fecha de julio de 2014, en donde lamenta y denuncia que el legislador 
2013 se han previsto que puedan ser de aplicación a los menores de 30 o de 35 años (en el caso de las mujeres) que deseen iniciar su actividad profesional por cuenta propia (SEMPERE NAVARRO, 2013, p. 1) ${ }^{55}$ y no empleen a trabajadores por cuenta ajena ${ }^{56}$. Entre las primeras se encuentran las que enumera el artículo 1 de esta ley y que pretenden incentivar a los jóvenes con la atribución de una reducción (durante 15 meses) de las cuotas a la Seguridad Social por contingencias comunes correspondientes, en función de la base de cotización elegida y el tipo aplicable. Reducción que será equivalente al $30 \%$ de la cuota que resulte de aplicar sobre la base mínima de cotización aplicable al tipo mínimo de cotización vigente en cada momento

haya tenido que recurrir a estas medidas incentivadoras para fomentar la contratación de parados, menguando así, por consiguiente, los ingresos de una precaria tesorería con el pretexto de impulsar una contratación laboral exhaustiva por las medidas de flexibilidad. Exponen así: "Con independencia de que tales incentivo provocan en realidad un efecto sustitutivo, es decir, no crean empleo neto sino que determinan el empleo de los integrantes de un colectivo en lugar de los de otros, y de que según la teoría económica el impacto de tales incentivos se halla muy desacreditado, pues se considera como una "lluvia de mayo" que refuerza una decisión ya tomada, pero en muy pocos casos mueve por sí misma a emplear, estas atractivas reducciones suponen otras tantas vías de agua para un barco que atraviesa momentos difíciles en varios de sus parámetros de gasto, como el de las prestaciones por desempleo o las pensiones, por lo que deberían suprimirse en todas sus fórmulas". Ver Archivo: "AESS. Comunicado. Tarifa plana y tarifa joven de la Seguridad Social (estudio; Lápiz Rosa).

${ }^{55}$ En opinión del profesor A. Sempere Navarro: "Contrasta la voluntad legislativa de la reforma laboral de 2012 que pretendía racionalizar a través de la supresión de las bonificaciones a la Seguridad Social la creación dispersa de estos incentivos con la creciente promulgación de normativa diversa que vuelve a fomentarlos y que crea una confusión en los empresarios ante el cúmulo de normas en materia de bonificaciones y reducciones a la Seguridad Social". 56 "Las bonificaciones y reducciones de cuotas previstas en la presente ley se financiarán con cargo a la correspondiente partida presupuestaria del Servicio Público de Empleo Estatal (SPEE) y se soportará por el presupuesto de ingresos de la Seguridad Social, respectivamente" (Disposición adicional primera, apartado 1 de la Ley 11/2013). "Las bonificaciones y reducciones de cuotas de la Seguridad Social se aplicarán por los emprendedores con carácter automático, sin perjuicio de su control y revisión por la Inspección de Trabajo y Seguridad Social, por la Tesorería General de la Seguridad Social y por el SPEE, en sus respectivos ámbito de competencia" (Disp. adicional $1^{\circ}$, apartado 2 de la Ley 11/2013). Para un estudio más completo ver, RODRÍGUEZ-PIÑERO Y BRAVO-FERRER, M y CASAS BAAMONDE, M.E: "El uso del Decreto Ley como instrumento de las reformas laborales. La garantía juvenil y la tarifa plana para el fomento del empleo y la contratación indefinida", Relaciones Laborales, $\mathrm{n}^{\circ}$ 4, 2014, página 6 de la edición digital. AARAGÓN GÓMEZ, C: "Una aproximación al cuadro actual de incentivo al empleo, haciendo especial referencia a la tarifa plana en la cotización a la Seguridad Social", en VV.AA, GARCÍA-PERROTE ESCARTÍN, I y MERCADER UGUINA, J.R: Las reformas laborales y de Seguridad Social de la Ley 11/2013 de 26 de julio al Real Decreto-Ley 3/2014, de 28 de febrero, Pamplona, Lex Nova- Thomsin Reuters, 2014, páginas: 196 y siguientes. 
(incluida la incapacidad temporal) $^{57}$. Asimismo, durante los 15 meses siguientes al término del periodo de reducción se podrán obtener una bonificación por el mismo importe que la antedicha reducción.

En el caso de los menores de 30 años que causen alta inicial en el Régimen Especial de Trabajadores Autónomos (RETA) o que no hubiesen estado en situación de alta en los cinco años inmediatamente anteriores, se podrán aplicar ciertas reducciones y bonificaciones sobre la cuota por causas comunes hasta un periodo máximo de 30 meses, siguiendo esta escala ${ }^{58}$ : (i) la reducción será equivalente al $80 \%$ de la cuota durante los 6 meses siguientes a la fecha del alta; (ii) al 50\% de la cuota en los posteriores 6 meses; (iii) al 30\% en los siguientes 3 meses; y (iv) se bonificará con el 30\% de la cuota en los 15 meses siguiente al término del periodo de reducción ${ }^{59}$.

Seguidamente, cabe destacar un conjunto de medidas que posibilitan para compatibilizar la prestación por desempleo con el trabajo por cuenta propia cuando así lo establezcan los programas de empleo destinados a colectivos con mayores dificultades de inserción laboral. Así pues, en tanto el programa de fomento al empleo lo permita, podrán los menores de 30 años que no tengan trabajadores a su cargo beneficiarse de esta posibilidad durante un máximo de 270 días y siempre que lo soliciten antes del plazo de 15 días desde el inicio de la actividad por cuenta propia (art. 2 y 3 de la Ley 11/2013).

En tercer lugar, aparecen en esta ley de 26 de julio del 2013 una ampliación de las posibilidades de aplicación de la capitalización de la prestación por desempleo. A este respecto, el artículo 4 permite que los menores de 30 años (o 35 años en el caso de mujeres) puedan percibir de una sola vez el 100\% del importe de la prestación por desempleo para su aportación al capital social de una mercantil de nueva constitución o constituida en un plazo máximo de 12 meses anteriores a su aportación $^{60}$. Ahora bien, será requisito indispensable que éstos desarrollen en la mercantil su actividad laboral con carácter indefinido ${ }^{61}$.

\footnotetext{
${ }^{57}$ Para las personas con un grado de discapacidad igual o superior al 33\% que se establezcan como trabajadores autónomos, la reducción y bonificación será del 50\% (en las mismas condiciones).
}

58 Cabe señalar que ambas bonificaciones y reducciones son perfectamente compatibles, siempre que no superen el plazo máximo de 30 meses.

59 Escala que se ha visto progresivamente ampliada en el caso de los trabajadores por cuenta propia con un grado de discapacidad igual o superior al 33\% que tengan menos de 35 años y que causen alta inicial o no hubiesen estado en situación de alta en los cinco meses inmediatamente anteriores. A saber: (i) la reducción será equivalente al 80\% durante los 12 meses y (ii) al 50\% durante los cuatro años siguientes.

${ }^{60}$ Se modifica así el apartado 1 de la disposición transitoria cuarta de la Ley 45/2002, de 12 de diciembre, de medidas urgentes para la reforma del sistema de protección por desempleo y mejora de la ocupabilidad (BOE núm. 298 de 13 de Diciembre de 2002).

${ }^{61}$ A este respecto, resulta interesante destacar que en por medio de la Ley 14/2013, de 27 de 
En cuarto lugar, se podrá suspender o reanudar el cobro de la prestación por desempleo cuando el trabajador autónomo haya realizado un trabajo por cuenta propia inferior a 24 meses o en el caso de los menores de 30 años, inferior a 60 meses (artículo 5 de la Ley 11/2013).

En quinto lugar, el legislador ha permitido que los menores de 30 años puedan voluntariamente decidir si cotizar o no por contingencias profesionales, incluida la cobertura por cese de la actividad (art. 6 de la Ley 11/2013).

En sexto lugar, para no penalizar excesivamente a los trabajadores pluriempleados, se reducen las cuotas de la Seguridad Social para aquellos que coticen en el Régimen General y en otro Régimen a tiempo completo cuando realicen una actividad económica alternativa. Se pretende de este modo de estimular nuevas altas en el RETA (arts. 28 y 29 -Título II- de la Ley 14/2013, de 27 de septiembre).

Adicionalmente, las leyes 11/2013 y 14/2013 disponen de otra serie de medidas, al margen de las de naturaleza social, que igualmente procuran impulsar y apoyar la actividad de los jóvenes emprendedores, a saber: 1) al objeto de frenar el excesivo número de gastos que supone el inicio en el desempeño del trabajo por cuenta propia, se han previsto diversas medidas de apoyo fiscal (por ejemplo: deducciones en el Impuesto de Valor añadido, Impuesto sobre Sociedades e Impuesto sobre la Renta de las Personas Físicas ${ }^{62}$; 2) se han introducido medidas para agilizar a través de los sistemas telemáticos todos y cada uno de los trámites para el arranque, ejercicio y cese de la actividad emprendedora (arts. 13 a 20 de la Ley 14/2013); 3) para apoyar la financiación del emprendimiento (arts. 31 a 35 de la Ley de 27 de septiembre de 2013); 4) de fomento del crecimiento y desarrollo de los proyectos empresariales (entre otros, se han creado medidas de simplificación de cargas administrativas -arts. 36 a 41-, para impulsar la contratación pública con emprendedores -arts. 42 a 47-, de simplificación de los requisitos de información económica financiera -arts. 48 y 49-); y por último, 5) con vistas no sólo a atraer inversión y talento a España, sino también a diseñar una estrategia de impulso de la internacionalización de la economía española, la ley 14/2013 ha impuesto el establecimiento de dos tipos de disposiciones, de un lado, aquellas que se destinan al fomento de la internalización (arts. 50 a 60) y, de otro lado, otras que inciden en la facilitación e incentivación de la movilidad internacional (arts. 61 a 76).

Un $2^{\circ}$ bloque de medidas lo conforman aquellos estímulos que se destinan hacia la inserción laboral de jóvenes por cuenta ajena y de creación de empleo (Título I, Capítulo III). Constituyen todos ellos mecanismos complementarios al ante-

septiembre, se han creado dos nuevas figuras mercantiles: de un lado, "el emprendedor de Responsabilidad limitada" (Capítulo II, artículos 7 a 11); y de otro lado, "la Sociedad Limitada de Formación Sucesiva" (Capítulo III, en su arts. 12).

${ }^{62}$ Arts. 7 y 8 de la Ley 11/2013 y arts. 23 a 27 de la Ley 14/2013. Además, téngase en cuenta la disposición final octava de la Ley 14/2013 por la que se modifica el art. 7 de la Ley $11 / 2013$. 
rior grupo, puesto que en la medida en que quede garantizado el crecimiento de los mercados (es decir, cuanto la tasa de desempleo en España se sitúe por debajo del $15 \%)$ se podrá entonces incentivar la contratación por cuenta ajena de trabajadores noveles. No obstante permiten también que, actualmente, empresas ya constituidas puedan contratar a jóvenes en desempleo al tiempo que adquieren una formación o una primera experiencia profesional.

En primer lugar, como mecanismo de estímulo hacia el empleo de carácter coyuntural se inserta la figura del contrato a tiempo parcial (art. 9 de la Ley 11/2013). Aunque la nueva ley no modifica en absoluto el régimen jurídico previsto para esta tipo de contratación por el art. 12 del Estatuto de los Trabajadores (ET) ${ }^{63}$, sí pretende aparentar, bajo la atribución de una serie de variantes a cumplir por la empresa y por el trabajador ${ }^{64}$ para la obtención de beneficios, que el fin último no es otro que el de fomento del empleo de los más jóvenes a través de la formación (LLEÓ CASANOVA, 2013, p. 15-18; SEMPERE NAVARRO, 2013, p. 3 y SIERRA BENÍTEZ, 2013, p. 224 Y 225.).

En lo que respecta a la empresa, incluidos trabajadores autónomos, que contraten a trabajadores menores de 30 años bajo esta forma jurídica: 1) tendrán derecho a disfrutar durante un máximo de 12 meses de una reducción de la cuota empresarial a la Seguridad Social por contingencias comunes del (a) 100\% cuando la plantilla de la empresa conste de menos de 250 trabajadores o (b) del $75 \%$ en empresas que ocupen 250 o más trabajadores ${ }^{65}$; 2) deberán no haber adoptado, en los seis meses anteriores a la celebración del contrato, decisiones extintivas improcedentes $\left.\left(1^{\circ} \text { límite }\right)^{66} ; 3\right)$ deberán mantener el nivel de empleo alcanzado con el contrato a

${ }^{63}$ Pudiendo éste ser por tiempo indefinido o por duración determinada, no debiendo la jornada ser superior al $50 \%$ de la correspondiente a un trabajador a tiempo completo comparable (art. 9.4 de la Ley 11/2013).

${ }^{64}$ A este respecto, se ha añadido un nuevo requisito a cumplir por el trabajador y es que deberá éste ser beneficiario del Sistema Nacional de Garantía Juvenil en España (Art. 9.2 en su letra e)). Véase, en este sentido, el número 2 del artículo 9 redactado por el artículo 4 del R.D.-ley 16/2013, de 20 de diciembre, de medidas para favorecer la contratación estable y mejorar la empleabilidad de los trabajadores («B.O.E.» 21 diciembre) y la letra e) del número 2 del artículo 9 introducida por el apartado uno del artículo 108 del R.D.-ley 8/2014, de 4 de julio, de aprobación de medidas urgentes para el crecimiento, la competitividad y la eficiencia («B.O.E.» 5 julio).

${ }^{65}$ Ahora bien, cuando el trabajador esté cursando formación o lo haya cursado en los seis últimos meses, podrá el disfrute de ese beneficio ser prorrogado por otros 12 meses (art. 9. 1 apartado segundo).

${ }^{66}$ Límite que afectará "únicamente a las extinciones producidas a partir del 24 de febrero de 2013, y para la cobertura de aquellos puesto de trabajo del mismo grupo profesional que los afectados por la extinción y para el mismo centro centros de trabajo" (art. 9.5 de la Ley 11/2013). 
tiempo parcial con vinculación formativa, al menos, por un periodo equivalente a la duración de dicha figura con un máximo de 12 meses desde su celebración ${ }^{67}$. En caso contrario se procederá al reintegro de los incentivos $\left(2^{\circ} \text { límite }\right)^{68}$.

Por su parte, los trabajadores deberán encontrarse en alguno de los siguientes supuestos: a) no tener experiencia laboral o que ésta sea superior a 3 meses; b) proceder de otro sector de actividad (SEMPERE NAVARRO, 2013, p. 3) ${ }^{69}$; c) ser desempleado y estar inscritos en la oficina de empleo durante los últimos 18 meses de manera ininterrumpida; d) carecer de título oficial de enseñanza obligatoria, de título de formación profesional o de certificado de profesional.

Se combinan en este modelo formación con empleo $^{70}$, no obstante, claramente la preferencia es a favor del segundo frente al primero. Efectivamente, la formación podrá no estar vinculada a la actividad a desarrollar ${ }^{71} \mathrm{y}$, de igual modo, no necesitará atribuírsela al trabajador durante el desempeño de la relación laboral ${ }^{72}$.

En segundo lugar, se presenta el contrato indefinido para microempresas y empresarios autónomos (art. 10 de la Ley 11/2013), el cual queda orientado hacia la contratación de menores de 30 años sin experiencia laboral en empresas de 9 o menos trabajadores. Por lo que a efectos de motivar dicha contratación, las empresas podrán beneficiarse de una reducción del $100 \%$ de la cuota empresarial a la Seguri-

${ }^{67}$ Ambos límites están presentes también en el contrato indefinido de un joven por microempresas y empresarios autónomos (art. 10 de la Ley 11/2013), y el primer empleo joven (art. 12 de la Ley 11/2013).

68 Se explicitan a continuación los supuestos en los que no se considerará incumplida la obligación de mantenimiento del empleo: 1) cuando se extinga por causas objetivas; 2) por despido disciplinario cuando uno u otro sea declarado o reconocido como procedente; 3 ) por extinciones causadas por dimisión, muerte, jubilación o incapacidad permanente total, absoluta o gran invalidez de los trabajadores; 4) expiración del tiempo convenido o realización de la obra o servicio objeto del contrato, o por resolución durante el periodo de prueba (art. 9.6 de la Ley 11/2013).

${ }^{69}$ A este respecto, considera el profesor A. Sempere Navarro, que la finalidad de esta regla no es otra que la de ofrecer una forma de recualificación para los trabajadores de los sectores más afectados por la crisis.

70 "Los trabajadores deberán compatibilizar el empleo con la formación..." (Art. 9.3 apartado primero de la Ley 11/2013).

71 "La formación, no teniendo que estar vinculada específicamente al puesto de trabajo objeto del contrato, podrá ser: a) Formación acreditable oficial o promovida por los servicios públicos de empleo; b) Formación en idiomas o tecnologías de la información y la comunicación de una duración mínima de 90 horas en cómputo anual" (Art. 9.3 apartado segundo de la Ley 11/2013). Téngase en cuenta también el RD 34/2008, de 18 de enero, por el que se regulan los certificados de profesionalidad (BOE núm. 27 de 31 de diciembre de 2008).

72 "... o justificar haberla cursado en los seis meses previos a la celebración del contrato" (Art. 9.3 apartado primero de la Ley 11/2013). 
dad Social por contingencias comunes durante el primer año ${ }^{73}$.

En tercer lugar, aparecen los incentivos a proyectos de emprendimiento joven (art. 11, Ley 11/2013). Destinados, básicamente, a aquellos emprendedores menores de treinta años y sin trabajadores asalariados que a fecha de 24 de febrero de 2013 contraten por primera vez y de forma indefinida (ya sea a tiempo completo o parcial) a personas desempleadas mayores de 45 años. A estos efectos, para concertar esta modalidad contractual, el trabajador deberá además cumplir alguno de los siguientes requisitos: (i) haber estado inscrito durante 12 meses en un plazo superior de 18 meses en la oficina de empleo; (ii) haber agotado su prestación por desempleo o; (iii) resultar beneficiario del programa de recualificación profesional (PREPARA $)^{74}$, lo que dará lugar a la concesión de una reducción del 100\% de todas las cuotas empresariales de Seguridad Social durante un periodo de 12 meses.

Con el título de "primer empleo joven" se enuncia, en cuarto lugar, uno de los instrumentos contractuales más criticados por la doctrina (LLEÓ CASANOVA, 2013, p. 1-12 y SEMPERE NAVARRO, 2013, p. 3) a causa de la temporalidad en el empleo contractual (art. 12, Ley 11/2013) ${ }^{75}$. En efecto, el legislador al introducir como causa justificativa para la contratación temporal la obtención de una primera experiencia profesional, en realidad lo que pretende es establecer la figura del contrato temporal no como mecanismo para responder a las necesidades temporales de trabajo en las empresas, sino como vía o trampolín de acceso al mercado de trabajo para los jóvenes menores de 30 años que carezcan de nula experiencia laboral o cuando sea ésta inferior a tres meses ${ }^{76}$.

No obstante y pese a lo expuesto, a simple vista choca bastante que pueda dirigirse este nuevo mecanismo a jóvenes que ya hayan trabajado anteriormente por

${ }^{73}$ Este contrato es incompatible con el "contrato indefinido de apoyo a emprendedores" que regula el art. 4 de la Ley 3/2012 (art. 10.2 letra a) de la Ley 11/2013).

${ }^{74}$ Véase la Resolución de 1 de agosto de 2013, del Servicio Público de Empleo Estatal, por la que se determina la forma y plazos de presentación de solicitudes y de tramitación de las ayudas económicas de acompañamiento incluidas en el programa de recualificación profesional de las personas que agoten su protección por desempleo prorrogado por el Real Decreto-ley 1/2013, de 25 de enero (BOE núm. 196, de 16 de agosto de 2013).

${ }^{75} \mathrm{Se}$ supone que uno de los aspectos que más se han criticado a nivel europeo es el excesivo recurso a la temporalidad en el empleo de los más jóvenes. Y es que con frecuencia se emplea esta vía de forma abusiva, gracias al concierto de condiciones laborales precarias.

${ }^{76}$ Recordemos que los contratos coyunturales no responden a una necesidad organizativa o productiva de la empresa, sino que su finalidad es el fomento del empleo. Hasta hoy día, los únicos contratos temporales coyunturales que encontrábamos en nuestro ordenamiento jurídico son los previstos por el art. 15 de la Ley 44/2007, de 13 de diciembre, para la regulación del régimen de las empresas de inserción (BOE núm. 299 de 14 de diciembre de 2007), modificado por la Ley 27/2009, de 30 de diciembre, de medidas urgentes para el mantenimiento y el fomento del empleo y la protección de las personas desempleadas (BOE núm. 315 de 31 de diciembre de 2009). 
un máximo de tres meses cuando, por el contrario, el rótulo de este precepto específicamente indica que la finalidad es la obtención de un "primer empleo". Ello plantea el interrogante de si en vez de hablar de "experiencia laboral" tenía el legislador de 2013 que haber seguido el mismo sentido que expresa el RD 1543/2011 de 31 de octubre, al regular las prácticas no laborales a jóvenes ${ }^{77}$ y diferenciar así entre los conceptos de "experiencia laboral" y "experiencia profesional" (LLEÓ CASANOVA, 2013, p. 3-4).

Se trata por tanto, de un contrato temporal propio con las excepciones establecidas por el art. 15.1 b) ET y que consta de una duración mínima de tres meses y una máxima de seis meses, ampliable a 12 meses cuando así se establezca por convenio colectivo sectorial -art. 12.2 de la Ley 11/2013- (LLEÓ CASANOVA, 2013, p. $10)^{78}$. Ahora bien este contrato podrá transformarse en indefinido al término del periodo mínimo de tres meses (SEMPERE NAVARRO, 2013, p. 3) ${ }^{79}$, lo que otorgará a la empresa ciertas bonificaciones en las cuotas empresariales a la Seguridad Social ${ }^{80}$.

Ciertamente, para alcanzar el objetivo que se pretende de "mejora de la empleabilidad en los jóvenes" no basta, en mi opinión, con esa breve duración de tiempo, sino que sería preciso que esa primera toma de contacto se ajustara al objetivo último de obtención de una formación profesional acreditable en los términos del RD 1224/2009 de 17 de julio, de reconocimiento de las competencias profesionales adquiridas por experiencia laboral (BOE núm. 205, de 25 de agosto de 2009) en desarrollo de la LO 5/2000 de 19 de julio, de las Cualificaciones y de la Formación Profesional (LLEÓ CASANOVA, 2013, p. 8-11). De igual modo, no pienso que pueda fomentarse la creación de empleo estable y de calidad para los jóvenes copiando las mismas fórmulas contractuales temporales existentes a día de hoy por el ET. Resul-

${ }^{77}$ Véase RD 1542/2011, de 31 de octubre por el que se regulan las prácticas no laborales en empresa (BOE núm. 278, de 18 de noviembre de 2011). Art. 1: "El presente real decreto regula las prácticas no laborales en empresas o grupos empresariales... dirigidas a personas jóvenes que, debido a su falta de experiencia laboral, tengan problemas de empleabilidad". Art. 3.1: "Las prácticas no laborales irán dirigidas a personas jóvenes desempleadas inscritas en la oficina de empleo, con edades comprendidas entre 18 y 25 años inclusive, que... no deberán haber tenido una relación laboral u otro tipo de experiencia profesional superior a tres meses en la misma actividad...".

${ }^{78}$ Para esta autora resulta incomprensible cómo mientras que en las prácticas no laborales en empresa la duración máxima es de nueve meses, en el tipo contractual establecido por el art. 12.2 la duración del contrato es inferior, a pesar de que la finalidad en ambas es la misma, esto es, la adquisición de una primera experiencia profesional en donde no se tiene en cuenta el nivel de cualificación del joven.

79 "El contrato es ciertamente un periodo de prueba ampliado...".

${ }^{80}$ Véase art. 12. 4 de la Ley 11/2013: "Las empresas..., que, una vez transcurrido un plazo mínimo de tres meses desde su celebración, transformen en indefinido los contratos a que se refiere este artículo tendrán derecho a una bonificación en las cuotas empresariales a la Seguridad Social... durante tres años". 
tará, por consiguiente, necesario que el legislador frene los actuales abusos a los que se encuentran sometidos los jóvenes mediante la imposición de medidas correctoras y limitadoras. De lo contrario, las cifras de trabajo precario se mantendrán y alzarán de manera estrepitosa en nuestro país.

En quinto lugar y como novedad, el art. 13 de la Ley 11/2013 ha modificado el régimen previsto para los contractos en práctica por el art. 11.1 del ET. Así pues, de un lado se ha elimina el límite temporal (de 5 años de manera general o de 7 en caso de discapacitados) para la obtención del título o certificado de profesionalidad habilitante para el desempeño del contrato en prácticas por menores de 30 años y de otro lado se ha concedido a los empresarios una bonificación del 50\% de la cuota empresarial por contingencias comunes durante la vigencia del contrato de trabajo. Ahora bien cuando se trate de trabajadores que al tiempo de dicha contratación estuviesen realizando prácticas no laborales en la empresa, la reducción será del 75\% (art. 13.2, Ley 11/2013) ${ }^{81}$. En el caso de que el contrato se formalice con personas beneficiarias del Sistema Nacional de Garantía Juvenil, se aplicará de forma adicional una bonificación del $50 \%$ cuando se contraten en prácticas a jóvenes menores de 30 años, aplicándose una reducción del 25 en la cuota empresarial a la Seguridad Social por contingencias comunes correspondiente al trabajador contratado durante toda la vigencia del contrato (medida que resultará aplicable a todas aquellas contrataciones que se efectúen hasta el 30 de junio de 2016) ${ }^{82}$.

En sexto lugar, se incorporan una serie de incentivos a la contratación de jóvenes en entidades de economía social (art. 14). Constituyen éstas bonificaciones a las cuotas empresariales de la Seguridad Social aplicables: a) a las cooperativas o sociedades laborales que incorporen trabajadores desempleados menores de 30 años como socios trabajadores o de trabajo y; b) a las empresas de inserción cuando dichos contratos sean subscritos por personas menores de 30 años en situación de exclusión social incluidas en el art. 2 de la Ley 44/2007, de 13 de diciembre, para la regulación del régimen de las empresas de inserción, en caso de contratación indefinida. Bonificaciones que no serán compatibles con las previstas en el art. 16.3 a) de la Ley 44/2007, de 13 de diciembre.

En lo que se refiere a los contratos para la formación y aprendizaje, la Ley 11/2013 ha modificado la prohibición que se establecía por el art. 10.2 de la Ley 14/1994 de 1 de junio ${ }^{83}$, al permitir ahora que las Empresas de Trabajo Temporal (ETTs) puedan celebrar estas fórmulas de contratación a las que antes no tenían ac-

${ }^{81}$ Téngase en cuenta también la Disposición final segunda de esta Ley 11/2013, por la que se modifica el art. $11.1 \mathrm{c}$ ) del ET para el contrato en prácticas.

${ }^{82}$ Nuevo apartado añadido por el Párrafo final del número 2 del artículo 13 introducido por el apartado tres del artículo 108 del R.D.-ley 8/2014, de 4 de julio, de aprobación de medidas urgentes para el crecimiento, la competitividad y la eficiencia («B.O.E.» 5 julio).

${ }^{83}$ Ley por la que se regulan las Empresas de Trabajo Temporal (BOE núm. 131, de 2 de junio de 1994). 
ceso. De este modo las ETTs podrán poner a disposición de una empresa usuaria a trabajadores contratados para la formación y aprendizaje conforme a lo previsto en el art. 11.2 del ET (Disposición adicional tercera y cuarta) ${ }^{84}$, pudiendo además beneficiarse de las bonificaciones y reducciones previstas para el primer empleo joven en el art. 12 de esta ley (Disposición adicional quinta). Por lo que la empresa usuaria actuará como si fuese la empleadora desde el inicio (SEMPERE NAVARRO, 2013, p. 4).

También se han previsto por la Ley 11/2013 una serie de medidas para la mejora de la intermediación laboral ${ }^{85}$ y seguimiento y evaluación de la Estrategia de Emprendimiento y Empleo Joven a través de la creación de una Comisión Interministerial ${ }^{86}$.

Finalmente, en el ámbito de la Comunidad Autónoma de Andalucía ${ }^{87}$ y con motivo del reparto de competencias entre Estado y CCAA (arts. 149.1.7 y 149.1.13 ${ }^{\mathrm{a}}$ Constitución Española), el Gobierno Andaluz junto a los Agentes Económicos y Sociales más representativos han consensuado el establecimiento de un listado de medidas para hacer frente al notable crecimiento de la inseguridad laboral y del desempleo juvenil ${ }^{88}$. Todo ello, por supuesto, en el marco del Acuerdo para el Progreso Económico y Social de Andalucía. Lo que finalmente ha motivado, como ya se ha dicho, la publicación del Decreto-Ley 8/2013, de 28 de mayo, de Medidas de Creación de Empleo y Fomento del Emprendimiento, convalidado por Resolución de 28 de junio del 2013. Normativa que viene a constituir fiel reflejo de las leyes 11/2013 y 14/2013 adoptadas a nivel estatal.

En esta normativa, principalmente, se pueden encontrar tres bloques de medidas: 1) aquellas que tienen por finalidad contribuir al empleo; 2) las que favore-

${ }^{84}$ Y también, por supuesto, en el RD 1529/2012, de 8 de noviembre, antes citado.

${ }^{85}$ Véase el Título I, Capítulo IV. Las medidas consisten, básicamente, en: a) la subscripción de acuerdos marco entre los servicios públicos de empleo y las entidades empresariales para la contratación de servicios que faciliten la intermediación laboral y b) la creación de un portal único de empleo, como garantía de transparencia y unidad de mercado.

86 Ver la Disposición Adicional segunda de la Ley 11/2013.

87 Véase el artículo 9 y $10.3 .1^{\circ}$ del Estatuto de Autonomía para Andalucía (Ley Orgánica 2/2007 de 19 de marzo).

${ }^{88}$ A este respecto, en su sesión de 12 de febrero de 2013 la Junta de Andalucía ha aprobado una serie de programas específicos que actuarán como plan de choque: 1) El Plan de Oportunidades Laborales de Andalucía (OLA); 2) Generación de empleo verde; 3) Plan de Fomento del Empleo Agrario 2013; 4) Plan extraordinario de Acción Social; 5) Programa de Promoción del Empleo Autónomo; 6) Programa de incentivos para el Fomento de la Innovación y el Desarrollo empresarial de Andalucía; y 7) Programa de Suelo Productivo. En lo que se refiere específicamente a la actividad emprendedora, el Instituto Andaluz de la Juventud ha creado los siguientes programas: a) el formativo en empleabilidad; b) la Escuela de Emprendedores; y 3) el Portal de Emancipación. 
cen la inversión productiva generadora de empleo y; 3 ) aquellas que tienen por objetivo el reforzamiento de las políticas activas de empleo y la mejora de los servicios de las oficinas de empleo del Servicios Andaluz de Empleo. De entre las líneas de actuación destinadas a incentivar el empleo juvenil destacan: a) el Programa Bono de Empleo Joven (Título II); b) el Programa de Apoyo y Fomento del Trabajo Autónomo (Título III); c) el programa de Apoyo a la Economía Social (Título IV), entre las que se encuentra, las Acciones de Fomento para las personas Emprendedoras menores de 35 años (línea 2) ${ }^{89}$ y; d) el Programa de Becas de Internalización para titulados superiores de formación profesional (Título V).

\section{Conclusiones}

A finales de la primera década de este siglo se produjo una grave crisis económica y financiera a nivel mundial. Obviando las causas y las pertinentes responsabilidades, son los efectos de la misma los que suponen el presente de la política social e internacional. El término más temido, pero a la vez más remarcable es el desempleo. Toda la UE ha sido azotada con esta lacra, lo que ha puesto en peligro la estabilidad política de la eurozona y su cohesión social. Como en toda crisis, los estamentos más débiles han sido los más perjudicados, especialmente la porción poblacional que incluye a los jóvenes. Aunque hay que reseñar, que si bien es cierto que todos los estados miembros han visto peligrosamente aumentado el paro juvenil, no todos han sufrido esta situación con la misma magnitud, lo que a la postre ha abierto comprometedoras grietas entre países que han corrido diferente suerte en este asunto.

La universalidad del problema ha suscitado una enorme preocupación a nivel comunitario, que ha tenido su respuesta en la adopción de diversas estrategias coordinadas entre los países miembros. Los máximos responsables europeos han llegado a una conclusión inevitable; una Europa cada vez más envejecida no puede darse el lujo de perder una generación completa de jóvenes formados, puesto que el porvenir de nuestras naciones ha de escribirse con sangre nueva. En este sentido la UE ha decidido poner en práctica una serie de medidas de choque contra el desempleo juvenil y su precariedad laboral. A la enorme masa de jóvenes desemplea-

${ }^{89}$ Busca sobre todo solventar las perentorias dificultades que encuentran los jóvenes empresarios para acceder al crédito de las entidades financieras dada la escasez o indisponibilidad crediticia, con el objetivo de fomentar la creación y mantenimiento del empleo. Algunas de las ayudas más destacadas que se han creado por la Junta de Andalucía son estas: 1) Fondo reembolsable para los trabajadores autónomos (FORAN-Empleo Autónomo); 2) Apoyo a la primera contratación del autónomo/autónoma; 3) Incentivos para trabajadores por cuenta propia; 4) Actuaciones dirigidas a emprendedores y empresarias; 5) incentivos para el autoempleo y créditos blandos; 6) Programas de Apoyo a la Economía Social: Fomento del Emprendimiento Social; 7) Programa de apoyo y fomento del trabajador autónomo; 8) Apoyo a la iniciativa empresarial joven en Andalucía...etc. 
dos hay que añadir a aquellos otros que conforman el colectivo "ni-ni”. Este último grupo se compone de personas que han perdido el rumbo en el panorama laboral y que con excesiva frecuencia incluye a jóvenes que han abandonado los estudios por varios motivos, pero entre los que se debe subrayar una fuerte desmotivación. Sin embargo, el más lamentable de los casos es el representado por los trabajadores precarios. Deplorable es el término que mejor define la realidad de este último colectivo, pues los términos y contratos de prácticas y aprendizaje, generalmente conocidos como temporales, con los que se inserta a los jóvenes al mercado laboral son sinónimo de abuso.

Concretamente la UE, aparte de las iniciativas generales ya comentadas, ha desarrollado la Estrategia para la Garantía del Empleo Juvenil, de aplicación obligatoria para aquellos estados miembros con una tasa de desempleo juvenil superior al 25\%. Por triste que pueda ser, España está incluida entre los estados que cumplen este dudoso mérito. Con este fin se ha puesto a disposición de estos países los fondos comunitarios, destinados a la creación de empleo de los más jóvenes, formación profesional y prevención de abandono escolar.

Siguiendo estas directrices se ha publicado en España la "Estrategia de Empleo 2012-2014", que pretende implantar un plan de medidas que garanticen la estabilidad en el empleo, el progreso económico y social y la igualdad de oportunidades. A pesar de que se han aprobado numerosos instrumentos normativos a nivel estatal, los más destacados son sin duda, la Ley 11/2013 de apoyo al emprendedor y de estímulo de crecimiento y de la creación de empleo y la Ley 14/2013 de apoyo a los emprendedores y su internacionalización. Y siguiendo su estela la Junta de Andalucía ha dictado el Decreto-Ley 8/2013 y ha acordado con las fuerzas sociales la adopción de una serie de medidas de creación de empleo y fomento del emprendimiento. Todas ellas son normativas muy heterogéneas, en las que se recogen entre otras una serie de incentivos de carácter fiscal y laboral, que van dirigidos a facilitar la creación de empresas por parte de los menores de 30 años o a fomentar su contratación por empresas ya constituidas.

Toda medida y actuación político-legislativa que busque una salida a la situación que se vive debe darse por bienvenida y ya habrá tiempo de corregir y adaptarse a la realidad. Es por ello que la enseñanza que contempla la normativa del emprendimiento deba resultar de inmediata implantación a todos los niveles educativos (Primaria, Secundaria, FP, Bachillerato) a fin de que cumpla sus objetivos y evite la cruda realidad que azota el mercado laboral. Y es que el desalentador exilio al que muchos jóvenes (incluidos los más preparados y capaces) se ven obligados a someterse al tener que emigrar a otros países en busca de oportunidades constituye, hoy día, un hecho cada vez más frecuente.

Pese a las buenas intenciones de las disposiciones de autoempleo, éstas adolecen de los mismo males que acucian al régimen jurídico del RETA. ¿Por qué? Porque para redactar la Ley de emprendedores el legislador se ha limitado a copiar 
de manera descarada, eso sí incorporando incentivos que actúen como incitadores, los mismos esquemas previstos actualmente para los trabajadores por cuenta propia. No se puede esperar nada mejor de lo que ya estamos presenciando diariamente en nuestro anquilosado mercado laboral. La aparición de "falsos autónomos" será un problema tan común con esta normativa como lo ha sido y sigue siendo en el RETA. No transcurrirá mucho tiempo para que surjan fraudes tan elementales como el representado por trabajadores asalariados que sean obligados por despóticos empresarios a darse de alta como trabajadores autónomos para eludir el pago de las cotizaciones a la Seguridad Social. Por otro lado, los casos de abusos a trabajadores autónomos económicamente dependientes, que en realidad no sean tales, sino simples trabajadores por cuenta ajena anegarán con suma facilidad el panorama laboral español. En este sentido, cabe preguntarse: ¿no estaremos asistiendo a un cambio sutil y soterrado del modelo de sistema de la Seguridad Social en el que predomine el régimen especial del RETA en detrimento del Régimen General de la Seguridad Social, con las consecuencias que ello conlleva?

En lo que respecta a las medidas de estímulo de empleo en las empresas se observa cómo se han incrementado los contratos temporales, en lugar de la contratación indefinida, lo cual es contrario a la razón de existencia misma de la Garantía Juvenil de la UE y a la exposición de motivos de la las leyes de emprendedores. Efectivamente, si el fin que persigue la UE es incentivar la el mantenimiento del empleo de los jóvenes, claramente se puede afirmar que este objetivo no se ha conseguido, pues todo ese conjunto de bonificaciones temporales no logrado todavía modificar la cultura empresarial española. Los contratos temporales más notables son el contrato a tiempo parcial, el contrato de primer empleo joven, el contrato en prácticas y el contrato para la formación y aprendizaje:

- El contrato a tiempo parcial ofrece las mismas condiciones previstas por el ET, con el consecuente predominio del empleo sobre la formación. Así tomará el papel de mero elemento de inserción ocupacional de jóvenes al ámbito laboral, favoreciendo el abuso sobre los mismos, tal y como sucede en la práctica hoy día.

- El contrato de primer empleo joven no es más que una mascarada, que oculta la realidad de su naturaleza. Bajo este término de contrato de primer empleo joven se esconde lo que normalmente se conoce como periodo de prueba, con lo que se favorece que las empresas produzcan la rotación en un mismo puesto de trabajo, deshaciéndose de cada "contratado" al término de este contrato temporal.

- El contrato en prácticas es igual al recogido en el ET, pero sin imponer límites que eviten el encadenamiento entre contratos temporales, concretamente entre el de formación y aprendizaje y el de prácticas, ya que el certificado de profesionalidad que se adquiere con el primero permite el 
acceso al segundo. En este caso los jóvenes profesionales se convierten en marionetas de la empresa o empresas correspondientes, entrando en una enloquecedora y funesta espiral en la que su vida laboral será, en el mejor de los casos, un rico compendio de contratos temporales.

- El contrato para la formación y aprendizaje está sujeto a las mismas condiciones del ET, sólo que en este caso se permite que las ETTs puedan concertar esta fórmula contractual, mecanismo al que no tenían acceso previamente. Además se concretan algunos aspectos de distribución de obligaciones de formación derivadas del marco de relaciones triangulares puestas en funcionamiento en virtud del contrato de puesta a disposición.

En definitiva, las leyes de emprendedores producidas a nivel estatal y autonómico en España como consecuencia de la Estrategia de Garantía Juvenil elaborada por la UE son elementos jurídicos interesantes que pretenden alcanzar objetivos loables, pero que cuentan con las mismas lagunas características de la normativa laboral vigente en España. Muy a nuestro pesar no parece que vayan a tener repercusiones positivas, sino que va a incrementar la precariedad laboral juvenil y la temporalidad en el empleo de uno de los sectores más indefensos y vulnerables de nuestra población activa. El futuro de nuestra sociedad será tan bueno como el trato que demos a las generaciones llamadas a sostener nuestra realidad social.

\section{Bibliografía}

AARAGÓN GÓMEZ, C (2014). Una aproximación al cuadro actual de incentivo al empleo, haciendo especial referencia a la tarifa plana en la cotización a la Seguridad Social. En García-Perrote Escartín, I y Mercader Uguina, J.R. Las reformas laborales y de Seguridad Social de la Ley 11/2013 de 26 de julio al Real Decreto-Ley 3/2014, de 28 de febrero. Pamplona: Lex Nova- Thomson Reuters.

HERNÁNDEZ BEJARANO, M (2013). La inserción de los jóvenes en el mercado laboral: un difícil reto para las políticas activas de empleo. En Cabeza Pereiro, J y Fernánez Prol, F (Coordinadores). Políticas de Empleo. Navarra: Thomson Reuters Aranzadi, Universidad de Vigo y Xunta de Galicia.

LLEÓ CASANOVA, B (2013). Novedades en materia de contratación laboral introducidas por el RD-Ley 4/2013, de 22 de febrero, de medidas de apoyo al emprendedor y de estímulo del crecimiento y de la creación de empleo. Revista General de Derecho del Trabajo y de la Seguridad Social, n 34, 2013.

MENGER, A (2004). El Estado democrático del trabajo, edición y estudio preliminar, "Derechos sociales y Estado democrático en Anton Menger", a cargo de J. L. Monereo Pérez. Granada: Ed. Comares.

MONEREO PÉREZ, J.L (2013). Nuevos contenidos de la Negociación Colectiva y 
límites legales de los mismos, con particular atención a la jubilación obligatoria y al periodo de prueba. Temas Laborales, monográficos sobre los efectos de la reforma laboral en la negociación colectiva, $\mathrm{n}^{\mathrm{o}} 120$.

MONEREO PÉREZ, J.L (2009). La política de empleo como instrumento para la lucha contra la precariedad laboral. Albacete: Bomarzo.

MONEREO PÉREZ, J.L; MOLINA NAVARRETE, C y MORENO VIDA, M ${ }^{\mathrm{a}} \mathrm{N}$ (2013). Manual de Derecho del Trabajo. Granada: Comares.

O'HIGGINS, N (2001). Desempleo juvenil y políticas de empleo. Una perspectiva global. Madrid: Colección Informes OIT núm. 54.

RODRÍGUEZ-PIÑERO Y BRAVO-FERRER, M y CASAS BAAMONDE, M.E (2014). El uso del Decreto Ley como instrumento de las reformas laborales. La garantía juvenil y la tarifa plana para el fomento del empleo y la contratación indefinida. Relaciones Laborales, $\mathrm{n}^{\circ} 4$.

SEMPERE NAVARRO, A (2013). Novedades Legislativas: Ley 11/2013, de 26 de julio, de medidas de apoyo al emprendedor y de estímulo del crecimiento y de la creación de empleo. Noticias Breves: Julio de 2013.

SIERRA BENÍTEZ, E.M (2013). Las medidas urgentes para la reforma del mercado laboral: aspectos laborales tras la promulgación de la Ley 3/2012. En VV.AA. Economía Española y Protección Social. Madrid: Asociación de Actuarios, Estadísticos y Economistas de la Seguridad Social.

SUÁREZ CORUJO, B (2014). Modalidades contractuales para jóvenes desde el paradigma de la precariedad. En García-Perrote Escartín, I y Mercader Uguina, J.R (Directs). Las reformas laborales y de Seguridad Social de la Ley 11/2013, de 26 de julio al Real Decreto-ley 3/2014, de 28 de febrero. Pamplona: Lex Nova- Thomson Reuters.

MONEREO ATIENZA, C y MONEREO PÉREZ, J.L (2012): La Europa de los Derechos. Estudio sistemático de la Carta de los Derechos Fundamentales de la Unión Europea. Granada: Comares.

VV.AA (2007). Empleo Juvenil en España. Madrid: Ministerio de Trabajo y Asuntos Sociales. 